ARTICLE

https://doi.org/10.1038/s41467-020-14686-2

\title{
Switchable encapsulation of polysulfides in the transition between sulfur and lithium sulfide
}

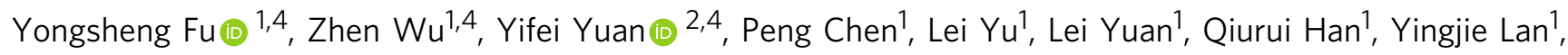
Wuxin Bai ${ }^{1}$, Erjun Kan ${ }^{1}{ }^{1}$, Chengxi Huang ${ }^{1}$, Xiaoping Ouyang ${ }^{3}$, Xin Wang ${ }^{1}$, Junwu Zhu ${ }^{1 凶} \&$ Jun Lu (i) ${ }^{2 凶}$

Encapsulation strategies are widely used for alleviating dissolution and diffusion of polysulfides, but they experience nonrecoverable structural failure arising from the repetitive severe volume change during lithium-sulfur battery cycling. Here we report a methodology to construct an electrochemically recoverable protective layer of polysulfides using an electrolyte additive. The additive nitrogen-doped carbon dots maintain their "dissolved" status in the electrolyte at the full charge state, and some of them function as active sites for lithium sulfide growth at the full discharge state. When polysulfides are present amid the transition between sulfur and lithium sulfide, nitrogen-doped carbon dots become highly reactive with polysulfides to form a solid and recoverable polysulfide-encapsulating layer. This design skilfully avoids structural failure and efficiently suppresses polysulfide shuttling. The sulfur cathode delivers a high reversible capacity of $891 \mathrm{mAh} \mathrm{g}^{-1}$ at $0.5 \mathrm{C}$ with $99.5 \%$ coulombic efficiency and cycling stability up to 1000 cycles at $2 \mathrm{C}$.

\footnotetext{
${ }^{1}$ Key Laboratory for Soft Chemistry and Functional Materials of Ministry of Education, Nanjing University of Science and Technology, Nanjing 210094 , China.

${ }^{2}$ Chemical Sciences and Engineering Division, Argonne National Laboratory, 9700 S. Cass Avenue, Lemont, IL 60439, USA. ${ }^{3}$ Key Laboratory of Low Dimensional Materials and Application Technology, School of Materials Science and Engineering, Xiangtan University, Xiangtan 411105, China. ${ }^{4}$ These

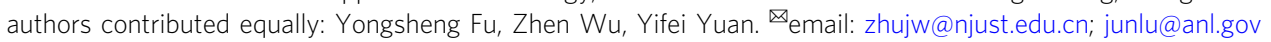


W ith the rapid development of electronic devices and electric vehicles, the demand for high-energy-density batteries has increased significantly over the past few decades $^{1-3}$. The lithium-sulfur (Li-S) battery is the most promising candidate to replace traditional lithium-ion batteries due to its high theoretical cathode capacity $\left(1675 \mathrm{mAh} \mathrm{g}^{-1}\right)$ and energy density $\left(2500 \mathrm{Wh} \mathrm{kg}^{-1}\right)^{4,5}$. Although significant improvements have been made in recent decades, serious challenges remain. The most notorious challenge is the rapid capacity decay and low coulombic efficiency that results when lithium polysulfides (LiPS) dissolve and diffuse in the electrolyte during the discharge/charge processes ${ }^{6}$.

Research on alleviating LiPS dissolution has focused on encapsulation in the sulfur electrodes of $\mathrm{Li}-\mathrm{S}$ batteries. Carbonbased materials such as micro/mesoporous carbons, carbon nanotubes, carbon nanofibres, hollow carbon spheres, and graphene are widely used to confine LiPS by physical encapsulation $^{7-15}$. To further enhance the interaction with polar LiPS, polar materials such as functionalized carbon materials (aminomodified reduced graphene oxide, nitrogen-doped mesoporous carbon), metal oxides, metal carbides, metal sulfides, metal nitrides, and polyoxometalates have also been investigated due to their strong chemical adsorption capacities ${ }^{16-27}$. These encapsulation strategies are generally effective at alleviating LiPS dissolution. However, because sulfur particles are preloaded to tightly fit the host geometry, they experience nonrecoverable structural failure arising from repetitive severe volume change during $\mathrm{S}-\mathrm{Li}_{2} \mathrm{~S}$ cycling. It is reasonably hypothesized that electrochemically constructing a recoverable protective layer at the electrode-electrolyte interface during $\mathrm{S}-\mathrm{Li}_{2} \mathrm{~S}$ cycling only when LiPS are present will solve this problem.

Technology is often inspired by nature. It is well known that hemostasis is a host's defence mechanism to preserve the integrity of the closed high-pressure circulatory system when bleeding occurs. This complex process involves several steps: vasoconstriction, platelet activation, thrombus formation, and thrombolysis. Among them, thrombus formation and thrombolysis are self-healing and recoverable processes in the blood vessel ${ }^{28-30}$. As shown in Fig. 1a, when an injury occurs, the platelets in the blood are activated and start to form a platelet plug or thrombus, which can sufficiently seal the damaged blood vessel wall to restrict bleeding. When the injured blood vessel is completely healed, the signal of dissolution of the clot is automatically received in the blood vessel, and the body recovers homeostasis.

The recoverable processes of thrombus formation and thrombolysis in the blood vessel inspired us to explore a unique LiPS encapsulation strategy where a skilfully designed electrolyte additive (analogous to the platelet) can interact only with LiPS to form a recoverable protective layer in situ. Benefiting from the additive's existence within the electrolyte, the protective layer is skilfully formed at the electrode-electrolyte interface rather than tightly surrounding each single sulfur particle, as previously reported in most studies. In addition, since the additive otherwise maintains its dissolved state when the electrode presents sulfur, the in situ formed protective layer thus senses no structural damage caused by the volume change of the sulfur electrode during $\mathrm{S}-\mathrm{Li}_{2} \mathrm{~S}$ transitions. The LiPS "clotting factors" (LiPSCFs) additive should meet at least three criteria: good dispersibility in the electrolyte, strong interaction with LiPS, and excellent restraining ability of the recoverable protective layer for the subsequent dissolution of LiPS.

Here in the present study, nitrogen-doped carbon dots (N-CDs) are chosen as LiPSCFs due to their low cost, facile fabrication and excellent dispersibility in electrolyte. The recoverable protective clotting layer of LiPS/N-CDs is clearly visualized in Li-S batteries both ex situ and in situ and blocks the subsequent dissolution and diffusion of LiPS. More interestingly, both discharge and charge involve the formation and dissolution of a protective LiPS/N-CDs clotting layer, similar to the recoverable processes of thrombus formation and thrombolysis in blood vessels but with $\mathrm{N}$-CDs functioning as activated platelets. As a result, this design efficiently avoids structural failure caused by the large volume change of the sulfur electrode and suppresses LiPS shuttling. Battery testing shows that the sulfur cathode can deliver a high reversible capacity of $891 \mathrm{mAh} \mathrm{g}^{-1}$ at $0.5 \mathrm{C}$ with $99.5 \%$ coulombic efficiency and cycling stability up to 1000 cycles.

\section{Results}

The strong interaction between the N-CDs and electrolyte and the formation of the LiPS/N-CDs clotting layer. To study the optical properties of the as-prepared N-CDs, photoluminescence measurements for the $\mathrm{N}-\mathrm{CD}$ in aqueous solution were carried out using different excitation wavelengths (Supplementary Fig. 1). Photoluminescence spectra of N-CDs show the strongest intensity at $380 \mathrm{~nm}$ excitation. As shown in Fig. 2a, the N-CDs have excellent dispersibility in the electrolyte of LiTFSI and $\mathrm{LiNO}_{3}$ dissolved in the cosolvents of DOL/DME. Even at a high N-CDs content of $5 \mathrm{wt} \%$, no solid precipitation can be found, demonstrating that the N-CDs satisfy the condition of good dispersibility as an ideal electrolyte additive. In contrast, the N-CDs are almost nondispersible/insoluble in the cosolvents of DOL/ DME (Supplementary Fig. 2). This might be a result of the strong interaction between the N-CDs and lithium salt (LiTFSI and $\mathrm{LiNO}_{3}$ ) due to the polar oxygen- and nitrogen-containing groups on the surface of the N-CDs (Supplementary Figs. 3, 4 and Supplementary Tables 1,2), which improves the dispersibility of the N-CDs in the cosolvents of DOL/DME. In this situation, it is desirable to obtain a protective clotting layer via the strong interaction between the N-CDs and LiPS to restrain the subsequent dissolution and diffusion of LiPS. To achieve this goal, $\mathrm{Li}_{2} \mathrm{~S}_{6}$ was dissolved in the cosolvents of DOL/DME and added isometrically into the electrolyte containing 0 and $0.3 \mathrm{wt} \%$ $\mathrm{N}$-CDs. As shown in Fig. 2b, a LiPS/N-CDs clotting layer is generated immediately upon adding the $\mathrm{Li}_{2} \mathrm{~S}_{6}$ solution into the electrolyte with $0.3 \mathrm{wt} \% \mathrm{~N}$-CDs. More interestingly, there was almost no color or volume change for the electrolyte containing $0.3 \mathrm{wt} \% \mathrm{~N}-\mathrm{CDs}$ after $30 \mathrm{~min}$, suggesting that the as-generated clotting layer can effectively prevent $\mathrm{Li}_{2} \mathrm{~S}_{6}$ diffusion into the electrolyte. Then, the mixture was violently shaken for $5 \mathrm{~min}$. As shown in Supplementary Fig. 5, it can be seen that the LiPS/ $\mathrm{N}$-CDs clotting layer was smashed, and the mixture retained the color of the $\mathrm{Li}_{2} \mathrm{~S}_{6}$ solution, demonstrating that not all $\mathrm{Li}_{2} \mathrm{~S}_{6}$ participated in the reaction with the N-CDs. In contrast, for the electrolyte without $\mathrm{N}-\mathrm{CDs}$, diffusion of the $\mathrm{Li}_{2} \mathrm{~S}_{6}$ into the electrolyte is obvious.

To further demonstrate the effect of N-CDs on LiPS clotting and the formation of the LiPS/N-CDs clotting layer, the electrodes (carbon paper) with $2 \mathrm{mg} \mathrm{cm}^{-2}$ sulfur loading were discharged at $0.5 \mathrm{~mA}$ in the electrolyte containing 0 and $0.3 \mathrm{wt} \%$ N-CDs, respectively (Supplementary Fig. 6). During discharge, the electrolyte without $\mathrm{N}-\mathrm{CDs}$ changed from colorless to bright yellow-green as a result of the dissolved LiPS. By comparison, the $0.3 \mathrm{wt} \% \mathrm{~N}-\mathrm{CDs}$ electrolyte remained light brown throughout, suggesting that the generated sulfur species were effectively confined in the cathode.

Therefore, the clotting layer formation could be seen more clearly, and nickel foam with a sulfur loading of $10 \mathrm{mg} \mathrm{cm}^{-2}$ was employed as the sulfur cathode and assembled onto the optically transparent Li-S cell. Figure $2 \mathrm{c}$ shows visual changes of the electrolyte and sulfur cathode in the optically transparent Li-S 
a

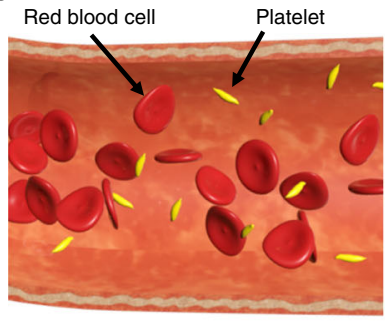

Blood vessel
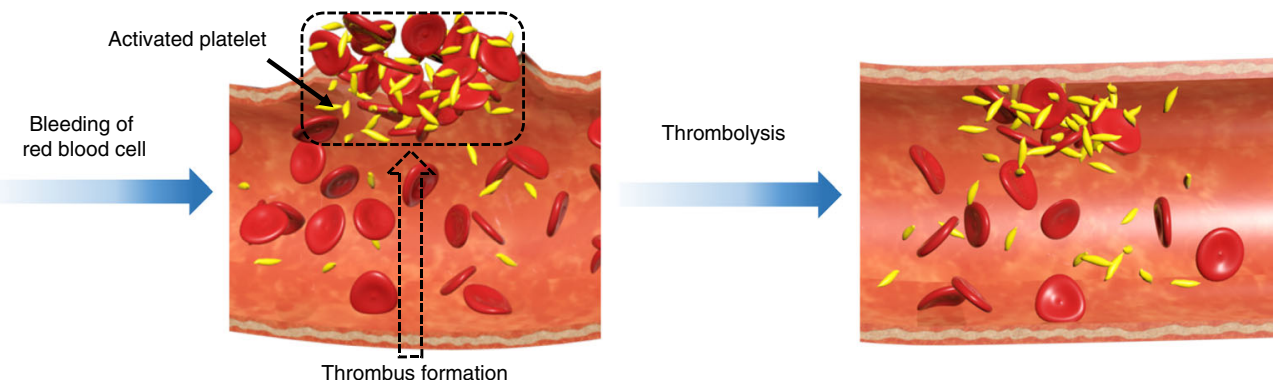

b
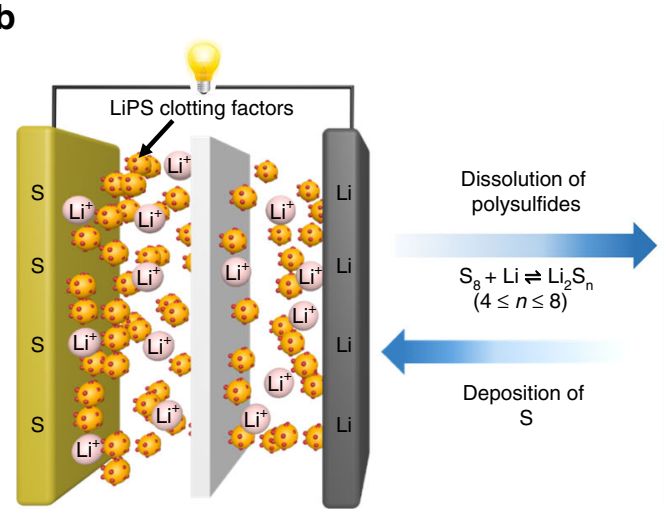

LiPS clotting layer formation
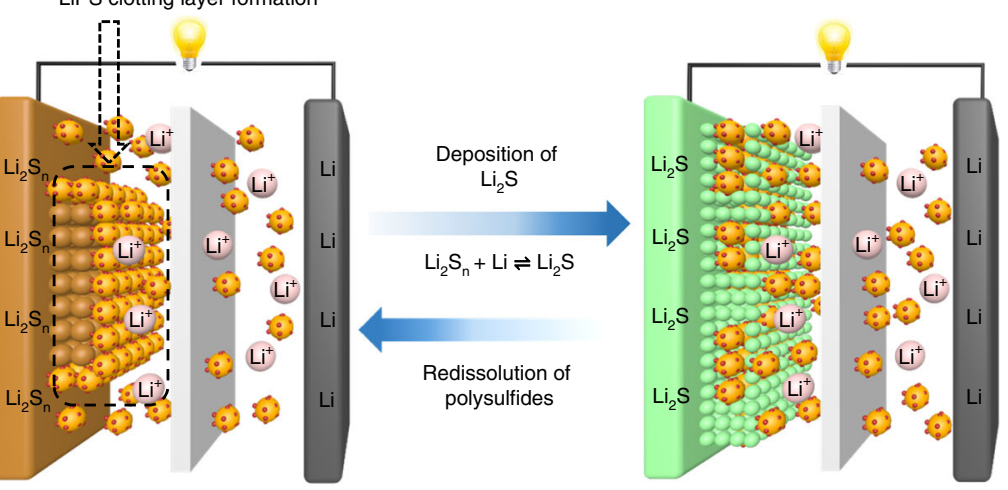

Fig. 1 Schematics of the blood coagulation and LiPS clotting mechanisms. a In mammals, when an injury happens in a vessel wall, the platelets become activated, triggering the formation of thrombus to stanch bleeding. After the wound is healed, thrombolysis occurs spontaneously. $\mathbf{b}$ Diffusion of LiPS in Li-S batteries can be effectively restrained by a recoverable protective clotting layer formed in situ from the reaction between dissolved LiPS and LiPS clotting factors at the electrode-electrolyte interface during the discharge/charge process.
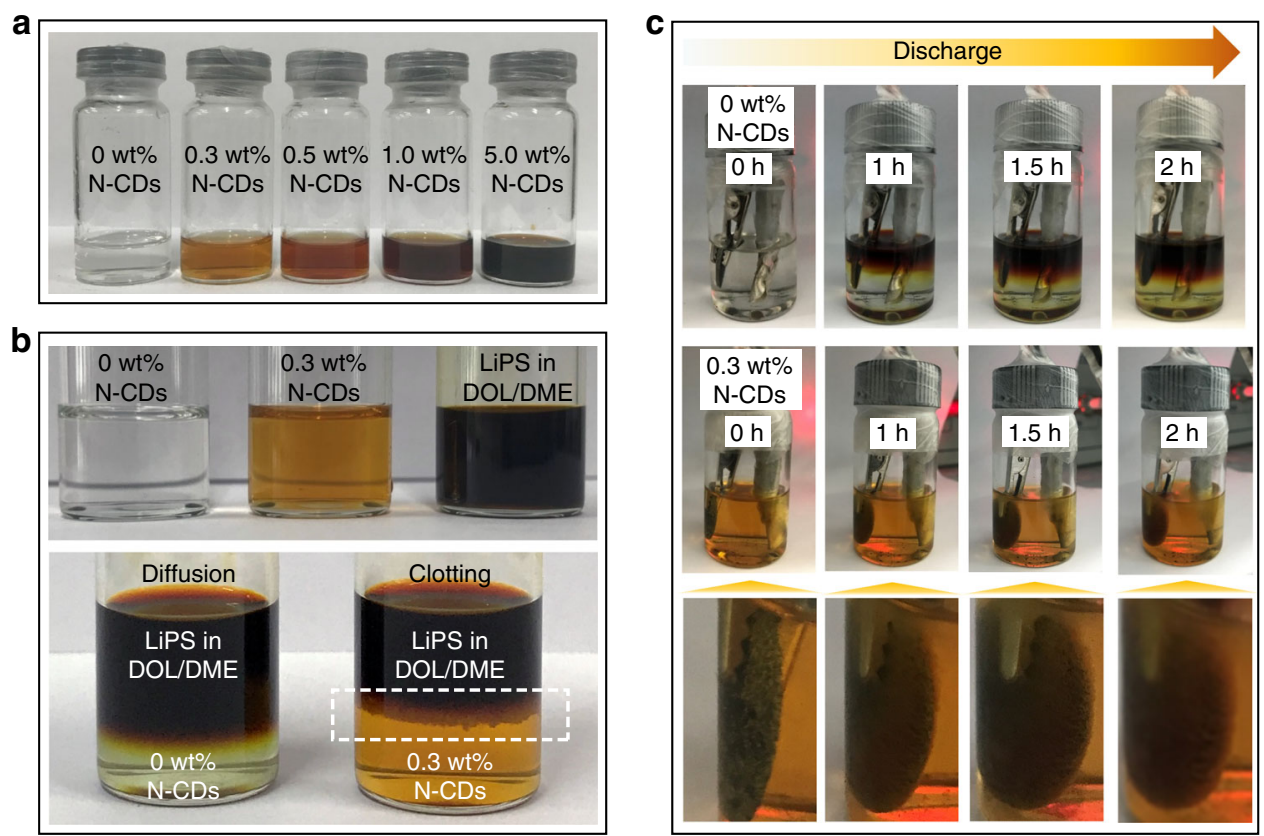

Fig. 2 Photographs showing the formation of chemical and electrochemical LiPS/N-CDs clotting layers. a Electrolyte with different $\mathrm{N}-\mathrm{CD}$ contents (O, $0.3,0.5,1.0$, and 5.0 wt\%). b Interaction between LiPS and electrolyte containing 0 and 0.3 wt $\% \mathrm{~N}-\mathrm{CDs}$. The white dashed frame highlights the formation of the protective layer at the LiPS/electrolyte interface. c Visual changes in the cell system during discharge in electrolytes containing 0 and 0.3 wt\% $\mathrm{N}$ CDs.

cell with 0 and $0.3 \mathrm{wt} \% \mathrm{~N}$-CDs electrolyte during discharge. For the cell without N-CDs, the color of the electrolyte appears reddish brown after $2 \mathrm{~h}$ of discharge, owing to the high concentration of long-chain LiPS. However, for the cell with $0.3 \mathrm{wt} \% \mathrm{~N}-\mathrm{CDs}$ electrolyte, the color of the electrolyte after $2 \mathrm{~h}$ of discharge is nearly the same as that at the beginning. More importantly, the sulfur cathode is covered with a thin LiPS/NCDs clotting layer after $1 \mathrm{~h}$ of discharge that becomes thicker as the discharge time increases, further confirming that $\mathrm{N}-\mathrm{CDs}$ possess a significant clotting function for LiPS and that the 

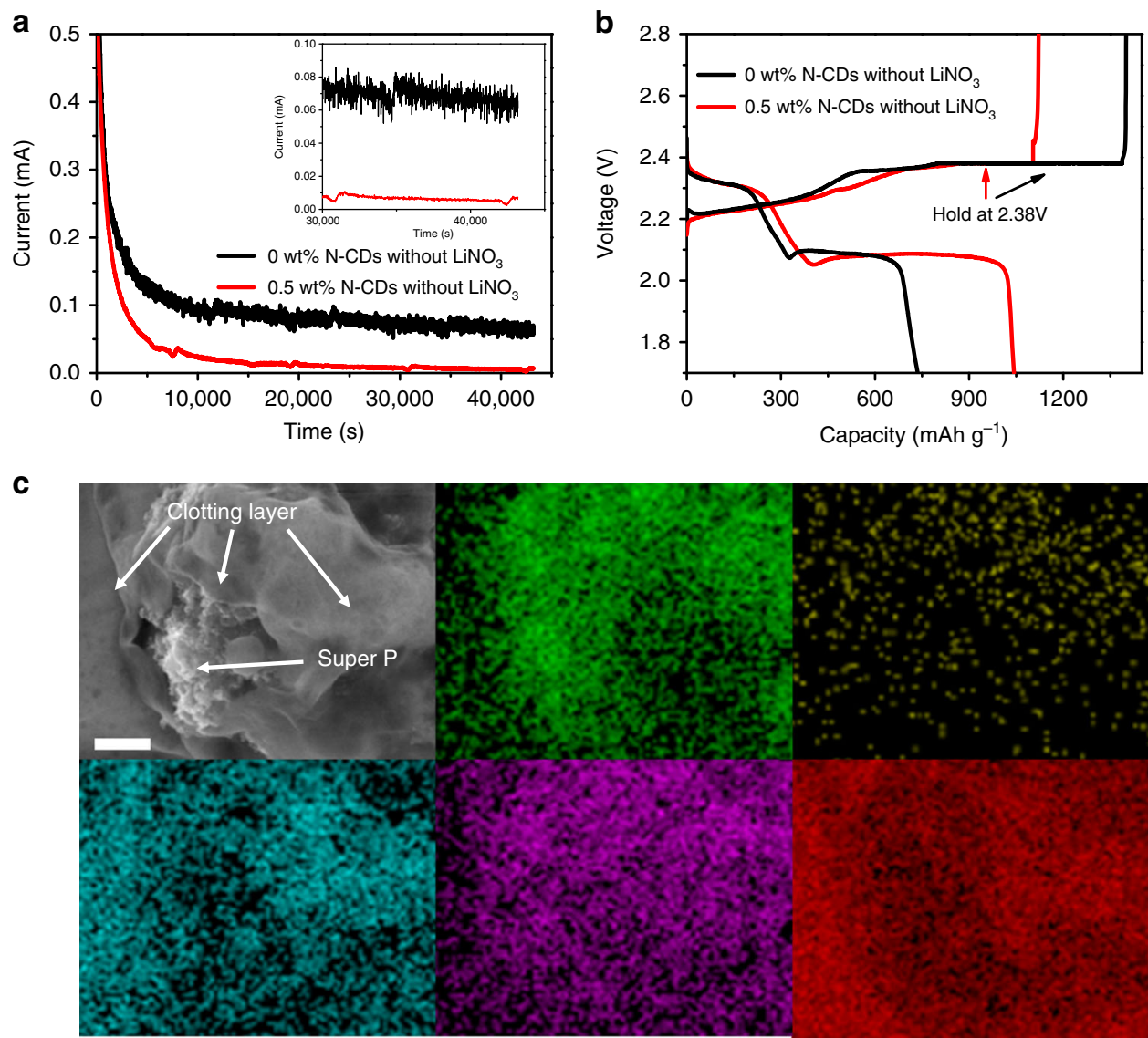

Fig. $\mathbf{3}$ Investigation of the clotting function of $\mathbf{N}-\mathbf{C D s}$ for LiPS in a $\mathbf{2 0 3 2}$ coin cell. $\mathbf{a}, \mathbf{b}$ Shuttle current measurement and discharge/charge curves of the coin cells with 0 and $0.5 \mathrm{wt} \% \mathrm{~N}-\mathrm{CDs}$ and without $\mathrm{LiNO}_{3}$ additive. The shuttle current measurement was held at $2.38 \mathrm{~V}$ for $43,200 \mathrm{~s}$ in the cycling process at $0.2 \mathrm{C}$. c SEM image and corresponding EDS elemental mapping of the sulfur cathode with $0.5 \mathrm{wt} \% \mathrm{~N}-\mathrm{CDs}$ at a discharge voltage of $2.1 \mathrm{~V}$. Green is for C, yellow is for $\mathrm{N}$, blue is for $\mathrm{O}$, purple is for $\mathrm{F}$ and red is for $\mathrm{S}$. Scale bar: $1 \mu \mathrm{m}$.

as-generated LiPS/N-CDs clotting layer suppresses LiPS dissolution and diffusion.

Studies have shown that the LiPS concentration is highest at a potential of $2.38 \mathrm{~V}$ during the discharge/charge process, resulting in a maximum shuttle current ${ }^{31,32}$. Here, 2032 coin Li-S cells with sulfur loading of $\sim 2 \mathrm{mg} \mathrm{cm}^{-2}$ were assembled without adding $\mathrm{LiNO}_{3}$ electrolyte, and the shuttle current was measured via $12 \mathrm{~h}$ potentiostatic testing at $2.38 \mathrm{~V}$. As shown in Fig. 3a, the shuttle current of the cell with $0.5 \mathrm{wt} \% \mathrm{~N}-\mathrm{CDs}$ is almost negligible $(7 \mu \mathrm{A})$, whereas the cell without $\mathrm{N}-\mathrm{CD}$ s has a $65 \mu \mathrm{A}$ shuttle current. It is clear that N-CDs provide considerable clotting function for LiPS, significantly preventing the subsequent dissolution and diffusion of LiPS and leading to enhanced electrochemical performance. As shown in Fig. $3 \mathrm{~b}$, the cell without N-CDs delivered low discharge capacity (736 $\mathrm{mAh} \mathrm{g}^{-1}$ ) and coulomb efficiency (52\%) arising from the fatal shuttling effect of LiPS, whereas the cell with $0.5 \mathrm{wt} \%$ $\mathrm{N}-\mathrm{CDs}$ exhibits superior discharge capacity $\left(1042 \mathrm{mAh}^{-1}\right)$ and high coulombic efficiency of $93 \%$, which can be ascribed to the clotting effect of N-CDs, significantly blocking the shuttle effect. The cell with $0.5 \mathrm{wt} \% \mathrm{~N}$-CDs was taken apart when the discharge voltage tapered to $2.1 \mathrm{~V}$, and the surface structure of the sulfur cathode was analysed by scanning electron microscopy (SEM) and energy dispersive spectroscopy (EDS). The LiPS/N-CDs clotting layer covering the super $\mathrm{P}$ surface can be clearly observed (Fig. 3c).

The formation mechanism of the LiPS/N-CDs clotting layer and superior electrochemical performance of $\mathrm{Li}-\mathrm{S}$ cells with 0.5 wt\% N-CDs. As shown in Supplementary Fig. 7a-d, N-CDs with an average diameter of $\sim 5 \mathrm{~nm}$ are uniformly dispersed in the electrolyte. The high-resolution transmission electron microscopy image shows that the N-CDs exhibit the characteristic lattice fringes of $0.208 \mathrm{~nm}$, corresponding to the (100) plane of graphite ${ }^{33,34}$. After being mixed with $\mathrm{Li}_{2} \mathrm{~S}_{6}$, the N-CDs in the electrolyte agglomerated to form larger clusters of less than $20 \mathrm{~nm}$ in size, suggesting that the N-CDs, similar to platelets, can serve as LiPSCFs to form the LiPS/N-CDs clotting layer.

The chemical interaction between the N-CDs and $\mathrm{Li}_{2} \mathrm{~S}_{6}$ (as a model compound of LiPS) was studied using X-ray photoelectron spectroscopy. As observed in Supplementary Fig. 7e, the highresolution $\mathrm{S} 2 \mathrm{p}$ spectrum of $\mathrm{Li}_{2} \mathrm{~S}_{6}$ shows two sulfur $2 \mathrm{p}_{3 / 2}$ peaks, at 161.4 and $163.0 \mathrm{eV}$, with an intensity ratio of $1: 2$, pointing to the terminal $\left(\mathrm{S}_{\mathrm{T}}{ }^{-1}\right)$ and bridging sulfur $\left(\mathrm{S}_{\mathrm{B}}{ }^{0}\right)$ atoms, respectively ${ }^{23}$. After interacting with the N-CDs, the bonding energy of $\mathrm{S}_{\mathrm{T}}{ }^{-1}$ shifts to $161.1 \mathrm{eV}$, suggesting an increased valence electron density on the sulfur atoms due to the interaction between the $\mathrm{N}$ $\mathrm{CDs}$ and $\mathrm{Li}_{2} \mathrm{~S}_{6}{ }^{35}$. The new peak at $167.2 \mathrm{eV}$ represents the binding energy of thiosulfate, which can be attributed to the surface redox reaction between chemisorbed oxygen on the N-CDs and $\mathrm{Li}_{2} \mathrm{~S}_{6}$. Thiosulfate can serve as an internal mediator to anchor and convert long-chain LiPS ${ }^{36}$. Supplementary Fig. 8 presents the FTIR spectra of $\mathrm{Li}_{2} \mathrm{~S}_{6}, \mathrm{~N}-\mathrm{CDs}$, and the interaction system of $\mathrm{N}$-CDs and $\mathrm{Li}_{2} \mathrm{~S}_{6}$. For pristine $\mathrm{Li}_{2} \mathrm{~S}_{6}$, the weak absorption peak at $482 \mathrm{~cm}^{-1}$ can be assigned to the typical stretching vibration of the S-S band. The peak position of the S-S band shifted to $503 \mathrm{~cm}^{-1}$ in the presence of $\mathrm{N}$-CDs, indicating that the strong interaction between $\mathrm{N}-\mathrm{CD}$ s and LiPS induces rotation and distortion of the S-S band of absorbed LiPS to form a stable configuration ${ }^{37}$. 

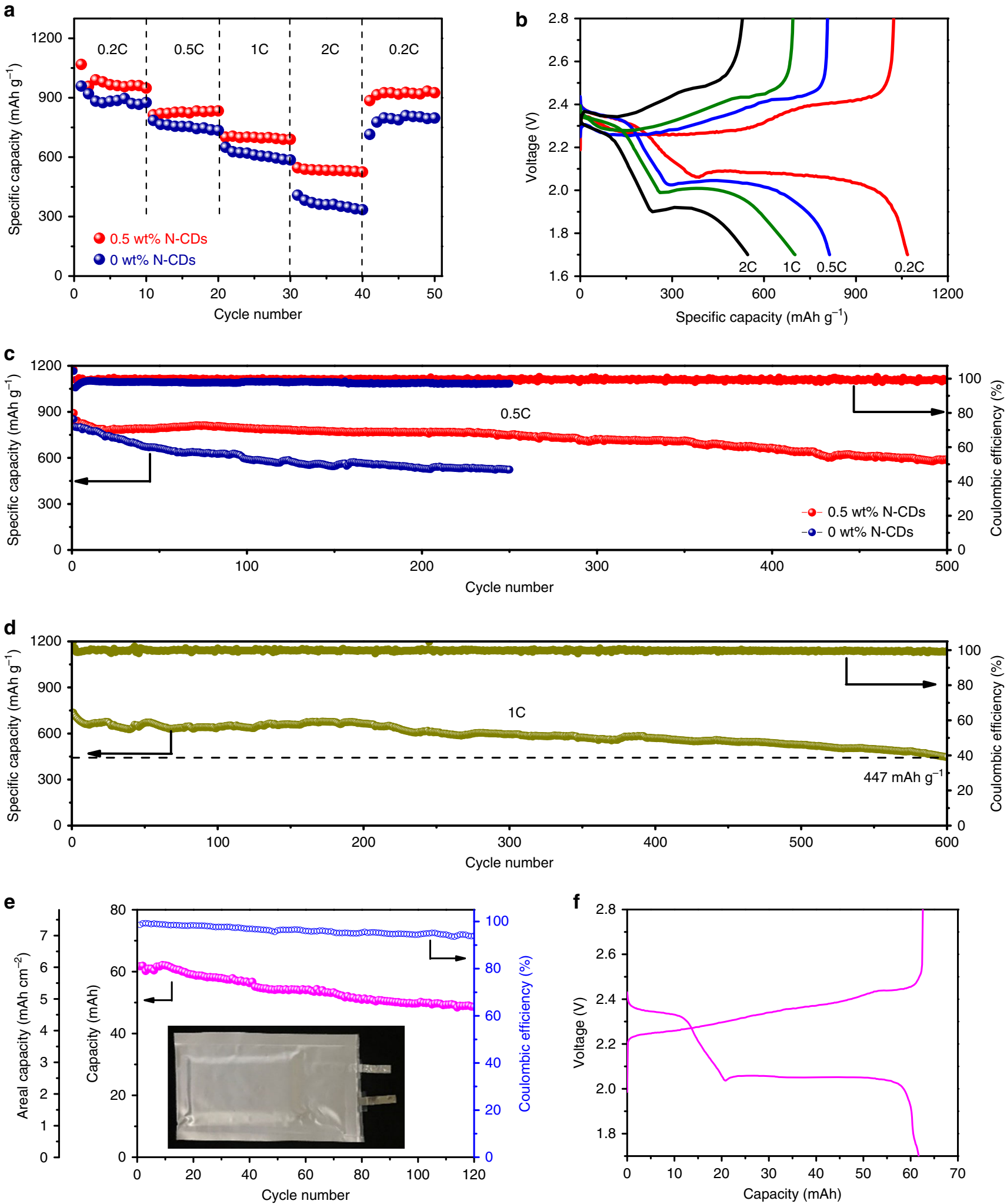

Fig. 4 The electrochemical performance of a Li-S cell with $\mathbf{0 . 5} \mathbf{w t} \% \mathbf{~} \mathbf{N}-\mathbf{C D s}$. a Rate performance of the cell with 0 and 0.5 wt $\%$ N-CDs electrolyte. $\mathbf{b}$ Voltage profiles of the cell with $0.5 \mathrm{wt} \% \mathrm{~N}$-CDs electrolyte at different current densities. c, $\mathbf{d}$ Long-term cycling performance of Li-S cells with $0.5 \mathrm{wt} \% \mathrm{~N}$-CDs electrolyte at 0.5 and $1.0 \mathrm{C}$. e, f Galvanostatic cycling performance and voltage profile for the Li-S pouch cell with 0.5 wt $\%$ N-CDs electrolyte at $0.2 \mathrm{C}$.

To evaluate the electrochemical performance of Li-S cells using $\mathrm{N}-\mathrm{CD}$ as the electrolyte additive, a series of electrochemical measurements was performed on the assembled 2032 coin cells with sulfur loading of $\sim 2 \mathrm{mg} \mathrm{cm}^{-2}$. As shown in Fig. $4 \mathrm{a}$, b and
Supplementary Fig. 9, the cell with $0.5 \mathrm{wt} \% \mathrm{~N}$-CDs electrolyte exhibits higher rate performances than the cells with $0,0.3$, and $1.0 \mathrm{wt} \% \mathrm{~N}-\mathrm{CDs}$ electrolyte, especially when the current density is high. The delivered discharge capacity of the cell with $0.5 \mathrm{wt} \%$ 
$\mathrm{N}-\mathrm{CD}$ is retained at 1068,814 , and $701 \mathrm{mAh} \mathrm{g}^{-1}$ at a current density of $0.2,0.5$, and $1.0 \mathrm{C}$, respectively. Even at a high current density of $2.0 \mathrm{C}$, there is still a high reversible capacity of $547 \mathrm{mAh} \mathrm{g}^{-1}$. When the current density returns to $0.2 \mathrm{C}$ after 40 cycles, the average discharge capacity is as high as $920 \mathrm{mAh} \mathrm{g}^{-1}$, demonstrating the beneficial clotting property of N-CDs for LiPS at high current rates. Supplementary Fig. 10 compares the galvanostatic discharge-charge profiles of $\mathrm{Li}-\mathrm{S}$ cells with 0 and $0.5 \mathrm{wt} \% \mathrm{~N}$-CDs electrolyte at $0.2 \mathrm{C}$. It can be seen that there are no obvious differences in the voltage profile, except for the higher specific capacity for the Li-S cell with $0.5 \mathrm{wt} \% \mathrm{~N}-\mathrm{CD}$ electrolyte. This may be ascribed to the fact that the LiPS/N-CDs clotting layer formed by the interaction between LiPS and N-CDs is just for addressing polysulfide dissolution and diffusion without changing the charge and discharge principles of Li-S batteries. As shown in Supplementary Fig. 11, two typical cathodic peaks at 2.33 and $1.98 \mathrm{~V}$ are ascribed to the reduction of sulfur to $\mathrm{Li}_{2} \mathrm{~S}_{x}$ $(4 \leq x \leq 8)$ and $\mathrm{Li}_{2} \mathrm{~S}_{2} / \mathrm{Li}_{2} \mathrm{~S}$, respectively. In the charge process, the overlapping anodic peaks are ascribed to the oxidation of $\mathrm{Li}_{2} \mathrm{~S}_{2} /$ $\mathrm{Li}_{2} \mathrm{~S}$ to $\mathrm{Li}_{2} \mathrm{~S}_{\mathrm{x}}$ and sulfur. Additionally, the cyclic voltammetry curves almost overlap with each other for the first five cycles, implying superior capacity retention capability and excellent cycling stability.

The long-term cycling performances of the cells with 0 and $0.5 \mathrm{wt} \% \mathrm{~N}$-CDs were tested at rates of $0.5,1.0$, and $2.0 \mathrm{C}$, respectively. As shown in Fig. 4c, the cell with $0.5 \mathrm{wt} \% \mathrm{~N}-\mathrm{CDs}$ delivers an initial discharge capacity of $891 \mathrm{mAh} \mathrm{g}^{-1}$ at $0.5 \mathrm{C}$. After 500 cycles, a capacity of $589 \mathrm{mAh} \mathrm{g}^{-1}$ is retained, corresponding to a low capacity decay rate of $0.067 \%$ per cycle with a coulombic efficiency of $99.5 \%$. It is worth noting that at much higher rates of 1.0 and $2.0 \mathrm{C}$, discharge capacities of $447 \mathrm{mAh} \mathrm{g}^{-1}$ over 600 cycles and $348 \mathrm{mAh} \mathrm{g}^{-1}$ over 1000 cycles, respectively, are still retained (Fig. $4 \mathrm{~d}$ and Supplementary Fig. 12). The capacity fluctuations are probably due to the volume fluctuations and redistribution of sulfur during the discharge/ charge processes ${ }^{23}$. In contrast, for the cell without N-CDs, the sulfur cathode suffers from much faster capacity decay $(0.149 \%$ per cycle) even at a low $\mathrm{C}$ rate. Moreover, the cell with $6.6 \mathrm{mg} \mathrm{cm}^{-2}$ sulfur loading and $0.5 \mathrm{wt} \% \mathrm{~N}$-CDs still delivers a high areal capacity of $5.8 \mathrm{mAh} \mathrm{cm}^{-2}$ and exhibits no obvious capacity decay after 200 cycles (Supplementary Fig. 13).

To further verify the practicability of this strategy, a Li-S pouch cell with $0.5 \mathrm{wt} \% \mathrm{~N}$-CDs electrolyte was assembled using carbonized cotton fiber foam (CFF) $/ \mathrm{Li}_{2} \mathrm{~S}_{6}$ with a low specific surface area of $3.1 \mathrm{~m}^{2} \mathrm{~g}^{-1}$ (Supplementary Fig. 14) as the cathode, which can reduce the weight ratio of electrolyte/active sulfur to $8: 1^{38}$. As shown in Fig. $4 \mathrm{e}$, a high area capacity of $6.0 \mathrm{mAh} \mathrm{cm}-2$ was achieved. After 120 cycles, the cell can still deliver a quite stable and high areal capacity of $4.7 \mathrm{mAh} \mathrm{cm}^{-2}$ due to the N-CDs clotting function for LiPS. Based on the total weight of their components and the average working voltages (Supplementary Table 3), the practical energy density of the $\mathrm{Li}-\mathrm{S}$ pouch cell was calculated to be $177 \mathrm{Wh} \mathrm{kg}^{-1}$.

Morphological changes in the sulfur cathode with 0 and $0.5 \mathrm{wt} \% \mathrm{~N}$-CDs in the electrolyte during the first discharge/charge process were observed using scanning electron microscopy SEM. At $0.5 \mathrm{wt} \% \mathrm{~N}-\mathrm{CDs}$, the pristine sulfur cathode consists of Super P and sulfur agglomerations before discharge (Supplementary Fig. 15). When the discharge voltage is tapered to $2.1 \mathrm{~V}$, the surface of the sulfur cathode becomes smooth and shiny compared to the pristine sulfur cathode (Fig. 5a), suggesting the formation of a clotting layer of LiPS/N-CDs. Proceeded to discharge to $2.0 \mathrm{~V}$, the surface of the sulfur cathode is mostly covered by a clotting layer of LiPS/N-CDs (Fig. 5b). The elemental mapping images indicate that the clotting layer contains C, N (2.6 wt\%), O, F, and S (Supplementary Fig. 16a), implying the coexistence of N-CDs and LiPS in the clotting layer. For the fully discharged sulfur cathode (1.7 V), the LiPS/N-CDs clotting layer is nearly fully replaced by hierarchical porous flower-like $\mathrm{Li}_{2} \mathrm{~S}$ crystals (Fig. 5c), which may facilitate rapid electron transfer and ion transport ${ }^{39}$.

A formation mechanism for hierarchical porous flower-like $\mathrm{Li}_{2} \mathrm{~S}$ crystals is proposed as follows: the LiPS in the LiPS/N-CDs clotting layer is in situ reduced to $\mathrm{Li}_{2} \mathrm{~S}$, and the $\mathrm{N}-\mathrm{CD}$ s function as the active sites for $\mathrm{Li}_{2} \mathrm{~S}$ crystal growth, giving rise to the temporary disappearance of the clotting layers. This formation mechanism is confirmed by elemental mapping (Supplementary Fig. 16b, c): $\mathrm{C}$ and $\mathrm{N}$ elements of $\mathrm{N}-\mathrm{CD}$ are uniformly dispersed in the flower-like $\mathrm{Li}_{2} \mathrm{~S}$ crystals, and the content of $\mathrm{N}$ element is as high as $2.2 \mathrm{wt} \%$, indicating that a considerable amount of N-CDs was used as nucleation sites.

During charging, as shown in Fig. 5d, e, the hierarchical porous flower-like $\mathrm{Li}_{2} \mathrm{~S}$ crystals are first oxidized to LiPS accompanied by the in situ formation of the LiPS/N-CDs clotting layer via the interaction between LiPS and N-CDs (2.4-2.3 V). For the fully charged sulfur cathode $(2.8 \mathrm{~V})$, almost all the LiPS is oxidized to sulfur, causing the disappearance of the LiPS/N-CDs clotting layers and the redispersion of $\mathrm{N}-\mathrm{CD}$ into the electrolyte (Fig. 5f). Moreover, there is no noticeable change in the surface morphology of the sulfur cathode even after 50 cycles (Supplementary Fig. 17), suggesting that the introduction of $\mathrm{N}$-CDs can not only restrain the dissolution and diffusion of LiPS but also facilitate the homogeneous electrochemical deposition of insulating sulfur, thus enhancing both the capacity and cycling performance. In contrast, for the sulfur cathode without N-CDs, there is serious dissolution and diffusion of LiPS throughout discharge and charge (Fig. $5 \mathrm{~g}-\mathrm{l}$ ), resulting in the loss of active materials from the surface of the sulfur cathode and poor electrochemical performance.

To further clarify the formation mechanism of the LiPS/N-CDs clotting layer clotting and the existing state of the N-CDs during the different discharge/charge processes for the assembled 2032 coin cells, XPS spectra were obtained for the sulfur cathode of the $\mathrm{Li}-\mathrm{S}$ cell with $0.5 \mathrm{wt} \% \mathrm{~N}$-CDs electrolyte at different charge/ discharge states. Figure 6a displays the Li 1s high-resolution XPS spectra. For the initial sulfur cathode, the peak at $55.7 \mathrm{eV}$ corresponds to the bonds of $\mathrm{Li}-\mathrm{N} / \mathrm{Li}-\mathrm{O}^{35}$, indicative of the strong interaction between LiTFSI and N-CDs. For the sulfur cathode at the state of $2.1 \mathrm{~V}$ (discharge), $1.7 \mathrm{~V}$ (full discharge) and $2.3 \mathrm{~V}$ (charge), there is a new peak located at $54.6 \mathrm{eV}$, indexed to the $\mathrm{Li}-\mathrm{S}$ bond, suggesting the presence of LiPS and $\mathrm{Li}_{2} \mathrm{~S}$. Importantly, the intensity of the $\mathrm{Li}-\mathrm{N} / \mathrm{Li}-\mathrm{O}$ bond increased significantly compared to that of the initial sulfur cathode, which can be ascribed to the generation of $\mathrm{LiPS}$ and $\mathrm{Li}_{2} \mathrm{~S}$, resulting in an increase in the $\mathrm{Li}-\mathrm{N} / \mathrm{Li}-\mathrm{O}$ bond. At the intermediate states of discharge $(2.1 \mathrm{~V})$ and charge $(2.3 \mathrm{~V})$, the as-generated LiPS can interact with the N-CDs to form a LiPS/N-CDs clotting layer at the sulfur electrode-electrolyte interface. At the state of full discharge $(1.7 \mathrm{~V})$, the LiPS in the LiPS/N-CDs clotting layer is in situ reduced to $\mathrm{Li}_{2} \mathrm{~S}$, and the $\mathrm{N}$-CDs function as nucleation sites for $\mathrm{Li}_{2} \mathrm{~S}$ crystal growth, giving rise to the temporary disappearance of the clotting layers. For the fully charged sulfur cathode $(2.8 \mathrm{~V})$, the Li 1 XPS spectra are nearly the same as that of the initial state of the sulfur cathode, implying the renewed dispersion of $\mathrm{N}-\mathrm{CD}$ into the electrolyte, which can be further confirmed by the XPS spectra of $\mathrm{N} 1 \mathrm{~s}$ and $\mathrm{O} 1 \mathrm{~s}$. As shown in Fig. 6b, c, the peaks of pyridinic $\mathrm{N}(398.9 \mathrm{eV})$, pyrrolic $\mathrm{N}$ $(399.7 \mathrm{eV})^{40}, \mathrm{C}-\mathrm{OH} / \mathrm{C}-\mathrm{O}-\mathrm{C}(532.2 \mathrm{eV})$ and $\mathrm{C}=\mathrm{O}(531.2 \mathrm{eV})^{41}$ bonds shift to lower bonding energy at the state of $2.1 \mathrm{~V}$ (discharge), $1.7 \mathrm{~V}$ (full discharge) and $2.3 \mathrm{~V}$ (charge), suggesting the enhancement of the electron cloud density on the $\mathrm{N}$ and $\mathrm{O}$ atoms owing to the strong interaction between $\mathrm{LiPS}$ or $\mathrm{Li}_{2} \mathrm{~S}$ and 

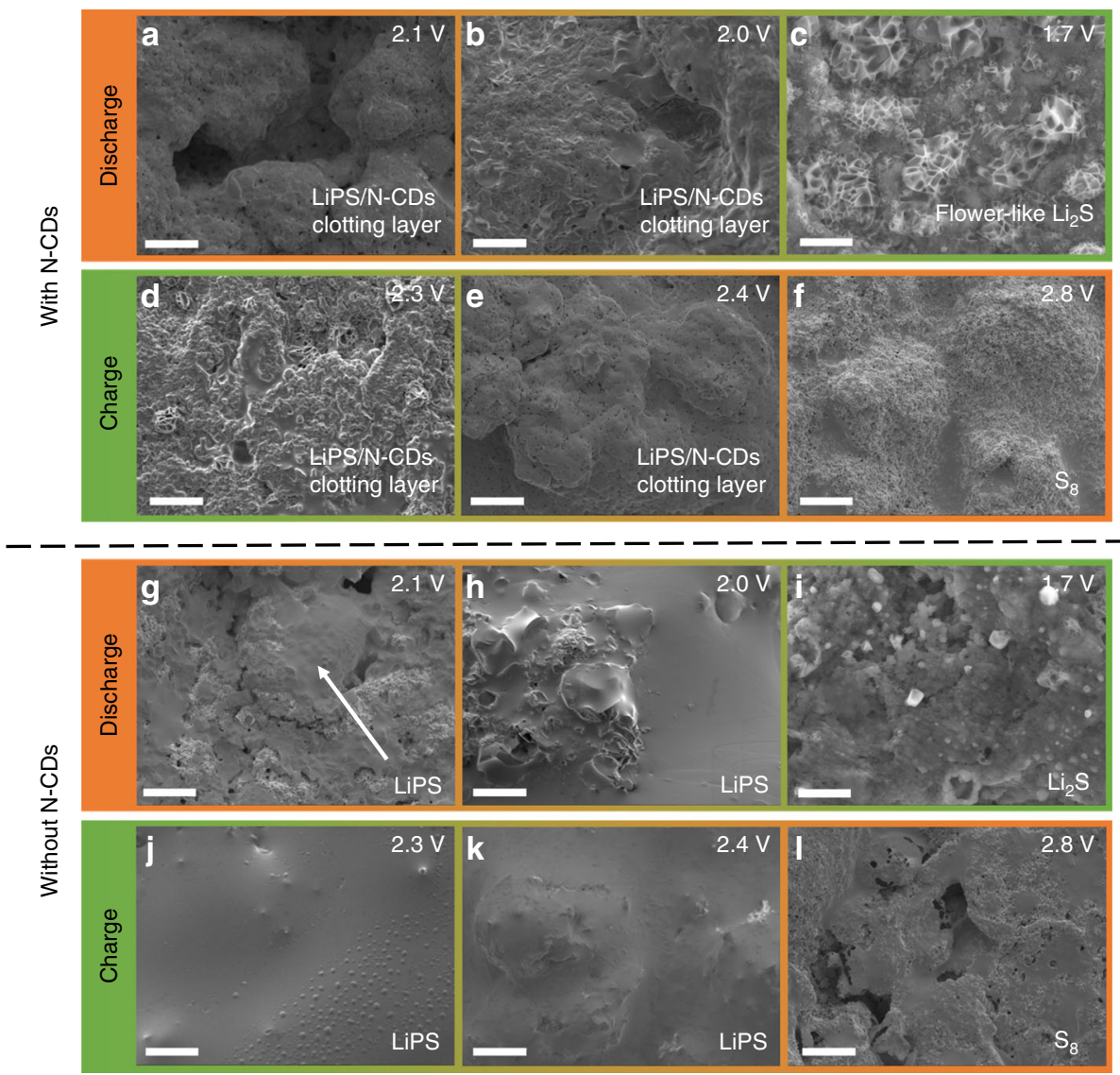

Fig. 5 Morphological change of the sulfur cathode surface in coin cells CR2032 loaded with $\mathbf{0}$ and 0.5 wt\% $\mathbf{N}$-CDs electrolyte during the first discharge/charge process. a-f SEM images of the sulfur cathode with $0.5 \mathrm{wt} \% \mathrm{~N}$-CDs electrolyte. $\mathbf{g}-\mathbf{I}$ SEM images of the sulfur cathode with 0 wt\% $\mathrm{N}$ CDs electrolyte. Scale bar: $10 \mu \mathrm{m}$.

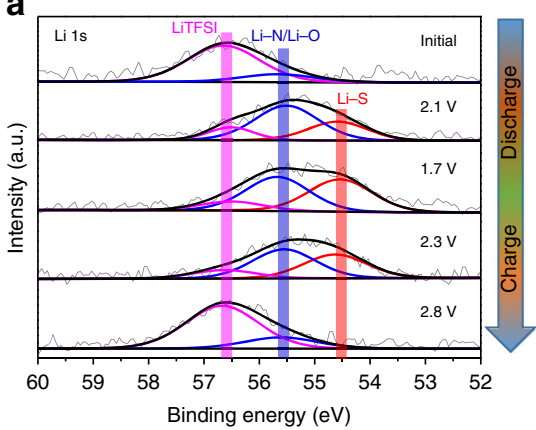

b

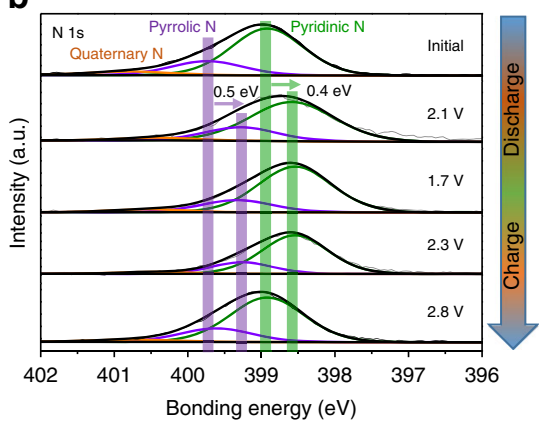

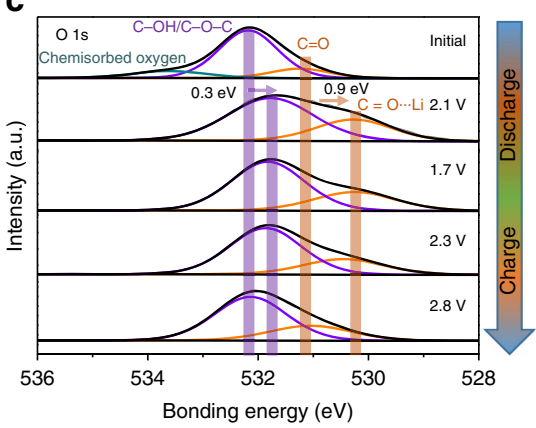

Fig. 6 XPS spectra of the sulfur cathode with $\mathbf{0 . 5} \mathbf{w t} \% \mathbf{N}-\mathrm{CDs}$ electrolyte at different charge/discharge states. a $L i \mathrm{~s}$, $\mathbf{b} \mathrm{N} 1 \mathrm{~s}$ and $\mathbf{c} O 1 \mathrm{~s}$.

$\mathrm{N}$-CDs. At the fully charged state of $2.8 \mathrm{~V}$, the peaks of $\mathrm{N} 1 \mathrm{~s}$ and $\mathrm{O} 1 \mathrm{~s}$ shift to the level of the initial state, further confirming the redispersion of $\mathrm{N}$-CDs into the electrolyte.

Previous research has found that pyridinic $\mathrm{N}$ exhibits the strongest binding to LiPS among all kinds of doped $\mathrm{N}$ species $^{16,21}$. However, the research does not provide a precise model for the simultaneous interaction of LiPS with pyridinic $\mathrm{N}$ and oxygen-containing groups simultaneously. It is therefore essential to theoretically understand the interaction of LiPS with both pyridinic $\mathrm{N}$ and oxygen-containing groups on the $\mathrm{N}$-CDs using density functional theory.

Our research found that the configuration of $\mathrm{Li}_{2} \mathrm{~S}_{4}$ simultaneously interacting with $\mathrm{C}=\mathrm{O}$ and pyridinic $\mathrm{N}$ is the most favorable structure for the formation of a strongly coupled clotting layer that preserves active materials and restrains the shuttle effect. Figure $7 \mathrm{a}-\mathrm{c}$ and Supplementary Fig. 18 show the optimized structures and binding energies of $\mathrm{Li}_{2} \mathrm{~S}_{4}$ binding to oxygen-containing groups $(-\mathrm{C}=\mathrm{O},-\mathrm{COOH}, \mathrm{C}-\mathrm{OH}, \mathrm{C}-\mathrm{O}-\mathrm{C})$ on the $\mathrm{N}-\mathrm{CD}$ and pyridinic $\mathrm{N}$ (doped at the center/edge of the $\mathrm{N}-\mathrm{CDs}$ ). $\mathrm{Li}_{2} \mathrm{~S}_{4}$ bridging simultaneously to $\mathrm{C}=\mathrm{O}$ and pyridinic $\mathrm{N}$ sites shows the highest binding energy $(3.694 \mathrm{eV})$ of the proposed structures.

This preferred configuration of $\mathrm{Li}_{2} \mathrm{~S}_{4}$ simultaneously interacting with $\mathrm{C}=\mathrm{O}$ and pyridinic $\mathrm{N}$ is further confirmed by the differential charge density and the corresponding partial density of states (PDOS). As shown in Fig. 7d, a clear charge transfer from a $\mathrm{Li}$ atom to the edge of the $\mathrm{N}-\mathrm{CD}$ can be observed, indicating a strong interaction between $\mathrm{Li}_{2} \mathrm{~S}_{4}$ and the edge of the $\mathrm{N}-\mathrm{CD}$, which could be mainly caused by the strong electronegativity of oxygen and nitrogen. It can be seen from the PDOS 
a
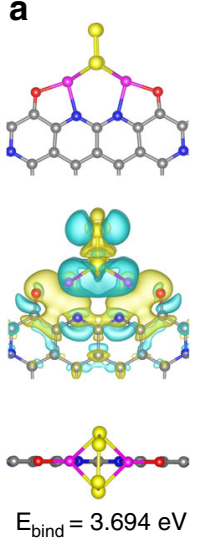

b
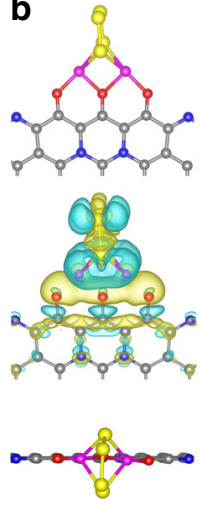

$E_{\text {bind }}=3.659 \mathrm{eV}$

$000 \% 0$

H Li C N O S
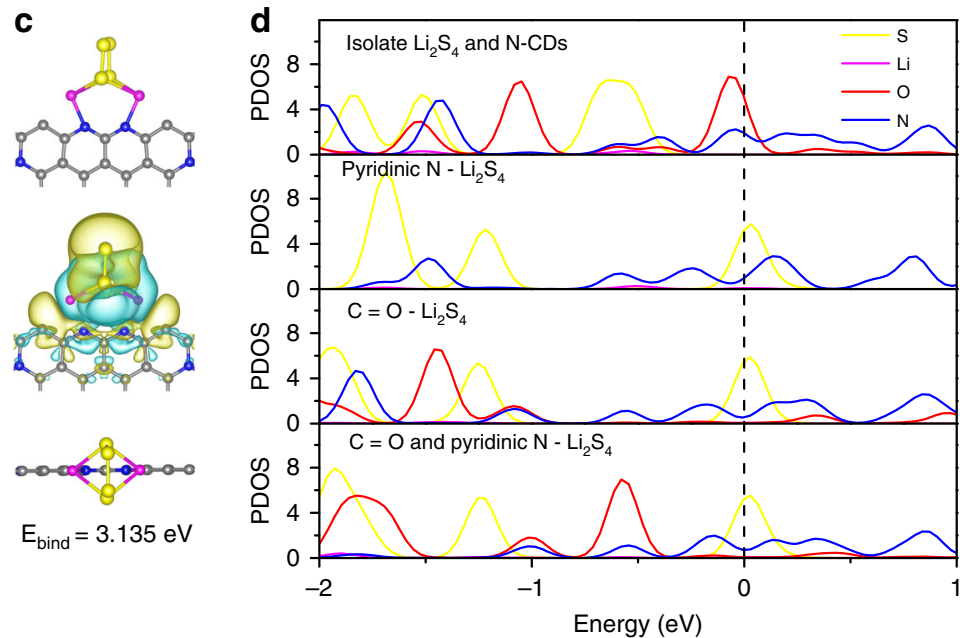

Fig. 7 Optimized structures, charge transfers, binding energies, and atomic partial density $\mathrm{Li}_{\mathbf{2}} \mathbf{S}_{\mathbf{4}}$ absorbed at different sites. a $\mathrm{C}=\mathrm{O}$ and $p y r i d i n i c \mathrm{~N}$ site. b $\mathrm{C}=\mathrm{O}$ site. c pyridinic $\mathrm{N}$ site. Here, yellow (blue) is the spatial region gain (loss) in charge. $\mathbf{d}$ Atomic partial density of states near the Fermi energy region for isolate $\mathrm{Li}_{2} \mathrm{~S}_{4}$ and $\mathrm{N}-\mathrm{CDs}$, $\mathrm{Li}_{2} \mathrm{~S}_{4}$ absorbed at pyridinic $\mathrm{N}$ and $\mathrm{C}=\mathrm{O}$ sites, respectively, and $\mathrm{Li}_{2} \mathrm{~S}_{4}$ absorbed at $\mathrm{C}=\mathrm{O}$ sites and pyridinic $\mathrm{N}$ sites simultaneously.

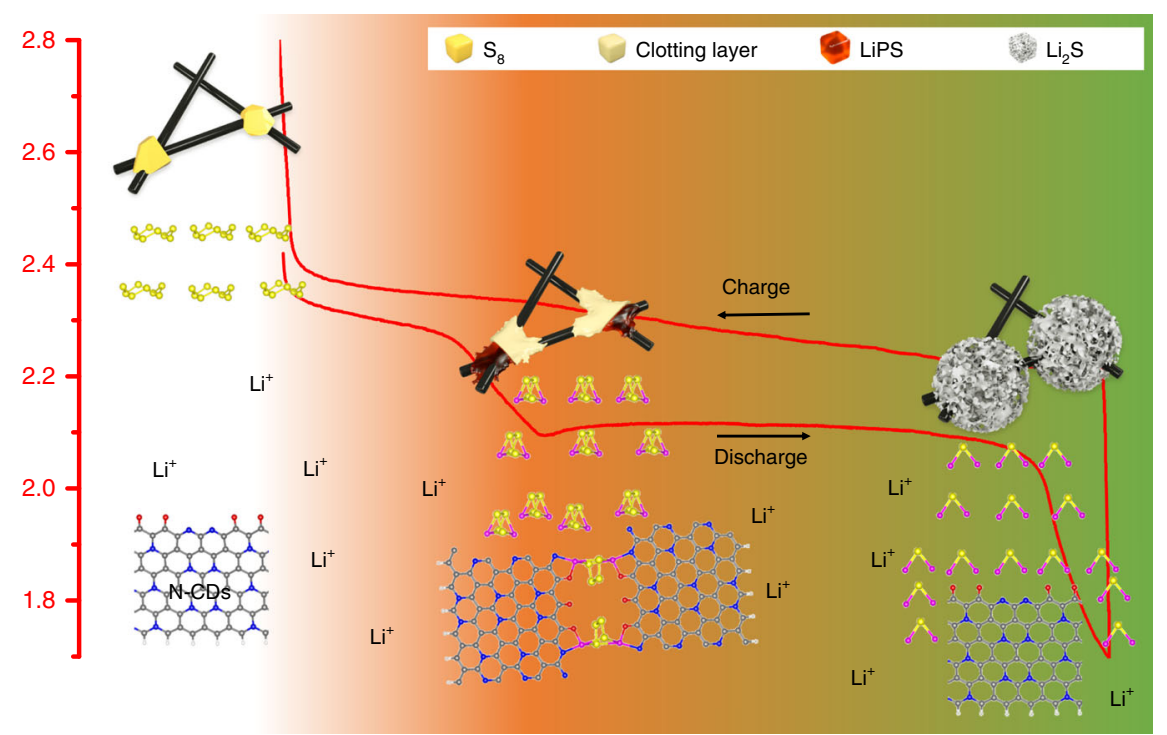

Fig. 8 Proposed LiPS clotting mechanism with $\mathbf{N}$-doped carbon dots as the clotting factors of LiPS during the discharge/charge process. The morphology changes of sulfur particles on the surface of carbon fibers as a function of discharge/charge status are depicted in the profile curve. The interaction mechanisms between the N-CDs and LiPS at the interface of the sulfur cathode/electrolyte are portrayed in the lower portion of the figure.

that the $\mathrm{O} 2 \mathrm{p}$ orbitals around the Fermi level are highly unsaturated before the adsorption of $\mathrm{Li}_{2} \mathrm{~S}_{4}$. After the adsorption of $\mathrm{Li}_{2} \mathrm{~S}_{4}$, the energy levels of the $\mathrm{O} 2 \mathrm{p}$ and $\mathrm{N} 2 \mathrm{p}$ orbitals shift downward, stabilizing the system ${ }^{42}$.

On the basis of our experimental results and theoretical analysis, a possible LiPS clotting mechanism is proposed in Fig. 8. First, the LiPS generated in the process of discharge interact with the N-CDs in the electrolyte to form a LiPS/N-CD clotting layer at the surface of the sulfur cathode, which prevents the subsequent dissolution and diffusion of LiPS and thus solidifies the sulfur cathode. Even though the expansion of the sulfur cathode may crack the initial clotting layer during discharge, causing the diffusion of LiPS, the highly dispersed N-CDs can capture the escaped LiPS and heal the gap. Then, during the discharge process, the LiPS in the LiPS/N-CDs clotting layer are reduced in situ to $\mathrm{Li}_{2} \mathrm{~S}$. With the $\mathrm{N}$-CDs serving as nucleation sites, the as-generated $\mathrm{Li}_{2} \mathrm{~S}$ grows into hierarchical porous flower-like $\mathrm{Li}_{2} \mathrm{~S}$ crystals, leading to the temporary disappearance of the clotting layers. During the charge process, the evolution of the protective layer is totally reversible. The discharge/charge process is analogous to thrombus formation and thrombolysis in the blood vessel, with N-CDs acting as activated platelets. The LiPS/N-CDs clotting layer can repeatedly generate and dissolve at the surface of the sulfur cathode during discharge/ charge, efficiently solidifying the intermediate LiPS and leading to enhanced electrochemical performance.

\section{Discussion}

Inspired by the recoverable processes of thrombus formation and thrombolysis in the blood vessel, we designed $\mathrm{N}$-doped carbon dots as analogous "blood platelets" in Li-S battery electrolytes. Upon the formation of dissolvable LiPS, N-CDs become activated and stimulate the formation of a protective layer at the sulfur 
electrode-electrolyte interface to suppress sulfur loss. This layer disappears when dissolvable LiPS are absent, as when the electrode is fully charged or discharged. The polysulfide-solidification capability of $\mathrm{N}$-CDs is due to the abundance of $\mathrm{N}$ atoms and surface oxygen-containing groups, which strengthen the interaction of $\mathrm{N}-\mathrm{CDs}$ with LiPS. As a result, high sulfur utilization and long-term cycling stability in Li-S batteries are achieved. We expect the encapsulation concept inspired by blood clotting to also be applied to battery electrochemistry beyond $\mathrm{Li}-\mathrm{S}$ to prevent the loss of active materials.

\section{Methods}

Synthesis of N-CDs. The N-CDs were synthesized through rapid one-step pyrolysis of ethanolamine according to the method described in Dong et al. ${ }^{33}$. A mixture of $4.5 \mathrm{~mL}$ hydrogen peroxide aqueous solution $(30 \%)$ and $3.0 \mathrm{~mL}$ ethanolamine in a $50 \mathrm{~mL}$ beaker was placed into an oven and calcined at $250^{\circ} \mathrm{C}$ for 10 min until dark colloidal N-CDs formed.

Preparation of sulfur cathode. The sulfur cathodes were fabricated using a slurry coating procedure. Sublimed sulfur, Super P, and polyvinylidene fluoride with a mass ratio of 70:20:10 were mixed into N-methyl-2-pyrrolidinone to form homogeneous slurry. The slurry was uniformly coated onto the carbon fibers and dried at $60^{\circ} \mathrm{C}$ under vacuum overnight, resulting in an areal sulfur loading of $2 \mathrm{mg} \mathrm{cm}{ }^{-2}$. Therefore, the formation of LiPS entrapments could be observed in situ, and a nickel foam electrode with a high areal sulfur loading of $\sim 10 \mathrm{mg} \mathrm{cm}^{-2}$ was prepared using the same procedure. In addition, electrodes with a high areal sulfur loading of $6.6 \mathrm{mg} \mathrm{cm}^{-2}$ for the coin cell and pouch cell were prepared by adding $0.5 \mathrm{M} \mathrm{Li}_{2} \mathrm{~S}_{6}$ in DOL/DME into the carbonized $\mathrm{CFF}^{43}$, followed by drying under vacuum overnight. The pouch cell was assembled by using $67.5 \mathrm{mg}$ of $\mathrm{S}$ active material and $540 \mathrm{mg}$ of $0.5 \mathrm{wt} \% \mathrm{~N}-\mathrm{CDs}$ electrolyte.

Characterization. Transmission electron microscopy and SEM images of the samples were acquired using an FEI Tecnai G2 F30 STWIN operating at $200 \mathrm{kV}$ and a JEOL 7800F, respectively. X-ray photoelectron spectroscopy analyses were performed using a Thermo Escalab 250 system with a monochromatic $\mathrm{Al} \mathrm{Ka}$ source $(h v=1486.6 \mathrm{eV})$. Photoluminescent spectra were recorded on a fluorescent spectrophotometer (F-4600, Hitachi). Fourier transform infrared spectra were obtained on a Bruker VERTEC 80v vacuum FT-IR spectrometer. The Bruker-Emmett-Teller (BET) surface area was determined by ASAP 2020 micromeritics.

Electrochemical measurements. CR2032 coin cells were assembled in an argonfilled glove box $\left(\mathrm{O}_{2}\right.$ and $\mathrm{H}_{2} \mathrm{O}$ levels $\left.<0.1 \mathrm{ppm}\right)$ for the electrochemical measurements, where the as-prepared sulfur electrode, Celgard 2500 membrane, and Li foil were used as the cathode, separator, and anode, respectively. The electrolyte was $1.0 \mathrm{~mol} \mathrm{~L}^{-1}$ lithium bis (trifluoromethanesulfonyl) imide (LiTFSI) and 1.0\% lithium nitrate $\left(\mathrm{LiNO}_{3}\right)$ dissolved in the cosolvents of 1,3-dioxolane (DOL) and 1,2-dimethoxyethane (DME) $(\mathrm{v} / \mathrm{v}=1: 1)$ with $\mathrm{N}$-CD additives of $0,0.3,0.5,1.0$, and $5.0 \mathrm{wt} \%$. The ratio of added electrolyte volume/active sulfur weight was set at $20 \mu \mathrm{L} \mathrm{mg}^{-1}$. Galvanostatic charge-discharge tests were carried out within the cutoff voltages of $1.7-2.8 \mathrm{~V}$ using a LAND CT2001A cell test instrument. The current density and the specific capacity were calculated according to the mass of elemental sulfur $\left(1 \mathrm{C}=1675 \mathrm{~mA} \mathrm{~g}^{-1}\right)$. For shuttle current measurement, cells with a sulfur loading of $\sim 2 \mathrm{mg} \mathrm{cm}^{-2}$ were assembled without adding $\mathrm{LiNO}_{3}$. In the cycling process at $0.2 \mathrm{C}$, the shuttle current of cells was detected via potentiostatic hold on charge at $2.38 \mathrm{~V}$. Cyclic voltammetry measurements were conducted on a Chenhua CHI-760 electrochemical workstation with a scan rate of $0.1 \mathrm{mV} \mathrm{s}^{-1}$ in the potential range of $1.7-2.8 \mathrm{~V}$.

Computational method. Our first-principles calculations were based on density functional theory with generalized gradient approximation for exchangecorrelation potential given by Perdew et al. ${ }^{44}$ as implemented in the Vienna ab initio simulation package ${ }^{45}$. The projector-augmented wave method $^{46}$ was used to treat the core electrons, and the valence electrons were represented using the planewave basis set. The planewave cut-off energy was set at $500 \mathrm{eV}$. The first Brillouin zone was sampled using a $\Gamma$-centred Monkhorst-Pack grid ${ }^{47}$. The convergence criteria for energy and force were set to $10^{-5} \mathrm{eV}$ and $0.02 \mathrm{eV} / \AA$, respectively. To simulate the surface adsorption of large molecules, a slab system with a vacuum space of $20 \AA$ along the $z$ direction was adopted. To simulate edge adsorption, a nanoribbon system with a vacuum space of $20 \AA$ along the $y$ and $z$ directions was adopted.

\section{Data availability}

All relevant data supporting the key findings of this study are available within the Article, Supplementary Information or available from the authors upon reasonable request.
Received: 9 August 2019; Accepted: 21 January 2020;

Published online: 12 February 2020

\section{References}

1. Bruce, P. G., Freunberger, S. A., Hardwick, L. J. \& Tarascon, J. M. Li- $\mathrm{O}_{2}$ and Li-S batteries with high energy storage. Nat. Mater. 11, 19-29 (2012).

2. Choi, N. S. et al. Challenges facing lithium batteries and electrical double-layer capacitors. Angew. Chem. Int. Ed. 51, 9994-10024 (2012).

3. Ji, X. \& Nazar, L. F. Advances in Li-S batteries. J. Mater. Chem. 20, 9821-9826 (2010).

4. Chung, S. H. \& Manthiram, A. Carbonized eggshell membrane as a natural polysulfide reservoir for highly reversible Li-S batteries. Adv. Mater. 26, 1360-1365 (2014).

5. Aurbach, D. et al. On the surface chemical aspects of very high energy density, rechargeable Li-sulfur batteries. J. Electrochem. Soc. 156, A694-A702 (2009).

6. Mikhaylik, Y. V. \& Akridge, J. R. Polysulfide shuttle study in the Li/S battery system. J. Electrochem. Soc. 151, A1969-A1976 (2004).

7. Schuster, J. et al. Spherical ordered mesoporous carbon nanoparticles with high porosity for lithium-sulfur batteries. Angew. Chem. Int. Ed. 51, 3591-3595 (2012)

8. Liang, C., Dudney, N. J. \& Howe, J. Y. Hierarchically structured sulfur/carbon nanocomposite material for high-energy lithium battery. Chem. Mater. 21, 4724-4730 (2009)

9. Sun, L. et al. Sulfur nanocrystals confined in carbon nanotube network as a binder-free electrode for high-performance lithium sulfur batteries. Nano Lett. 14, 4044-4049 (2014)

10. Zhao, Y., Wu, W., Li, J., Xu, Z. \& Guan, L. Encapsulating MWNTs into hollow porous carbon nanotubes: a tube-in-tube carbon nanostructure for high-performance lithium-sulfur batteries. Adv. Mater. 26, 5113-5118 (2014).

11. Zheng, G. et al. Amphiphilic surface modification of hollow carbon nanofibers for improved cycle life of lithium sulfur batteries. Nano Lett. 13, 1265-1270 (2013).

12. Singhal, R., Chung, S. H., Manthiram, A. \& Kalra, V. A free-standing carbon nanofiber interlayer for high-performance lithium-sulfur batteries. J. Mater. Chem. A 3, 4530-4538 (2015).

13. Zhang, C., Wu, H. B., Yuan, C., Guo, Z. \& Lou, X. W. Confining sulfur in double-shelled hollow carbon spheres for lithium-sulfur batteries. Angew. Chem. Int. Ed. 51, 9592-9595 (2012).

14. Yu, M., Li, R., Wu, M. \& Shi, G. Graphene materials for lithium-sulfur batteries. Energy Storage Mater. 1, 51-73 (2015).

15. Wu, Z. et al. Three-dimensional graphene hollow spheres with high sulfur loading for high-performance lithium-sulfur batteries. Electrochim. Acta 224, 527-533 (2017)

16. Wang, Z. et al. Enhancing lithium-sulfur battery performance by strongly binding the discharge products on amino-functionalized reduced graphene oxide. Nat. Commun. 5, 5002 (2014).

17. Peng, H. J. et al. Strongly coupled interfaces between a heterogeneous carbon host and a sulfur-containing guest for highly stable lithium-sulfur batteries: mechanistic insight into capacity degradation. Adv. Mater. Interfaces $\mathbf{1}$, 1400227 (2014).

18. Tang, C. et al. Nitrogen-doped aligned carbon nanotube/graphene sandwiches: facile catalytic growth on bifunctional natural catalysts and their applications as scaffolds for high-rate lithium-sulfur batteries. Adv. Mater. 26, 6100-6105 (2014)

19. Qiu, Y. et al. Highly nitridated graphene- $\mathrm{Li}_{2} \mathrm{~S}$ cathodes with stable modulated cycles. Adv. Energy Mater. 5, 1501369 (2015).

20. Seh, Z. W. et al. Stable cycling of lithium sulfide cathodes through strong affinity with a bifunctional binder. Chem. Sci. 4, 3673-3677 (2013).

21. Song, J. et al. Nitrogen-doped mesoporous carbon promoted chemical adsorption of sulfur and fabrication of high-areal-capacity sulfur cathode with exceptional cycling stability for lithium-sulfur batteries. Adv. Mater. 24, 1243-1250 (2014)

22. Seh, Z. W. et al. Sulphur- $\mathrm{TiO}_{2}$ yolk-shell nanoarchitecture with internal void space for long-cycle lithium-sulphur batteries. Nat. Commun. 4, 1331-1336 (2013).

23. $\mathrm{Ni}$, L. et al. Core-shell structure and interaction mechanism ofy- $\mathrm{MnO}_{2}$ coated sulfur for improved lithium-sulfur batteries. Small 13, 1603466 (2017).

24. Zhou, F. et al. Low cost metal carbide nanocrystals as binding and electrocatalytic sites for high performance Li-S batteries. Nano Lett. 18, 1035-1043 (2018),

25. Chen, T. et al. Self-templated formation of interlaced carbon nanotubes threaded hollow $\mathrm{Co}_{3} \mathrm{~S}_{4}$ nanoboxes for high-rate and heat-resistant lithium-sulfur batteries. J. Am. Chem. Soc. 139, 12710-12715 (2017)

26. Deng, D. R. et al. $\mathrm{Co}_{4} \mathrm{~N}$ nanosheet assembled mesoporous sphere as a matrix for ultrahigh sulfur content lithium-sulfur batteries. ACS Nano 11, 6031-6039 (2017). 
27. Ye, J. C. et al. Strategies to explore and develop reversible redox reactions of $\mathrm{Li}-\mathrm{S}$ in electrode architectures using silver-polyoxometalate clusters. J. Am. Chem. Soc. 140, 3134-3138 (2018).

28. Furie, B. \& Furie, B. C. Molecular and cellular biology of blood coagulation. $N$. Engl. J. Med. 326, 800-806 (1992).

29. Long, A. T. et al. Contact system revisited: an interface between inflammation, coagulation, and innate immunity. J. Thromb. Haemost. 14, 427-437 (2016).

30. Giangrande, P. L. Six characters in search of an author: the history of the nomenclature of coagulation factors. Brit. J. Haematol. 121, 703-712 (2003).

31. Moy, D., Manivannan, A. \& Narayanan, S. R. Direct measurement of polysulfide shuttle current: a window into understanding the performance of lithium-sulfur cells. J. Electrochem. Soc. 162, A1-A7 (2015).

32. Peng, H. J. et al. A cooperative interface for highly efficient lithium-sulfur batteries. Adv. Mater. 28, 9551-9558 (2016).

33. Dong, X. et al. Fast one-step synthesis of $\mathrm{N}$-doped carbon dots by pyrolyzing ethanolamine. J. Mater. Chem. C 2, 7477-7481 (2014).

34. Yuan, Y., Amine, K., Lu, J. \& Shahbazian-Yassar, R. Understanding materials challenges for rechargeable ion batteries with in situ transmission electron microscopy. Nat. Commun. 8, 15806 (2017).

35. Liu, W. et al. Ultrathin dendrimer-graphene oxide composite film for stable cycling lithium-sulfur batteries. Proc. Natl Aacd. Sci. USA 114, 3578-3583 (2017).

36. Liang, X. et al. A highly efficient polysulfide mediator for lithium-sulfur batteries. Nat. Commun. 6, 5682 (2015).

37. Chen, Y. et al. Polysulfide stabilization: a pivotal strategy to achieve high energy density Li-S batteries with long cycle life. Adv. Funct. Mater. 28, 1704987 (2018).

38. Agostini, M. et al. Minimizing the electrolyte volume in Li-S batteries: a step forward to high gravimetric energy density. Adv. Energy Mater. 8, 1801560 (2018).

39. Pan, H. et al. Non-encapsulation approach for high-performance Li-S batteries through controlled nucleation and growth. Nat. Energy 2, 813 (2017).

40. Li, F. et al. The synergistic effect of pyridinic nitrogen and graphitic nitrogen of nitrogen-doped graphene quantum dots for enhanced $\mathrm{TiO}_{2}$ nanocomposites' photocatalytic performance. Catalysts 8, 438 (2018).

41. Oh, Y. J. et al. Oxygen functional groups and electrochemical capacitive behavior of incompletely reduced graphene oxides as a thin-film electrode of supercapacitor. Electrochim. Acta 116, 118-128 (2014).

42. Zhang, Q. et al. Understanding the anchoring effect of two-dimensional layered materials for lithium-sulfur batteries. Nano Lett. 15, 3780-3786 (2015).

43. Fang, R. et al. 3D interconnected electrode materials with ultrahigh areal sulfur loading for Li-S batteries. Adv. Mater. 28, 3374-3382 (2016).

44. Perdew, J. P., Burke, K. \& Ernzerhof, M. Generalized gradient approximation made simple. Phys. Rev. Lett. 77, 3865 (1996).

45. Kresse, G. \& Hafner, J. Ab initio molecular dynamics for liquid metals. Phys. Rev. B 47, 558-561 (1993).

46. Blöchl, P. E. Projector augmented-wave method. Phys. Rev. B 50, 17953 (1994).

47. Monkhorst, H. J. \& Pack, J. D. Special points for Brillouin-zone integrations. Phys. Rev. B 13, 5188-5192 (1976).

\section{Acknowledgements}

This work was supported by the National Natural Science Foundation of China (51772156, 51772152, and 51872144), the Natural Science Foundation of Jiangsu Province (BK20180019 and BK20171423), and PAPD of Jiangsu. Work at Argonne National Laboratory was supported by the U. S. Department of Energy (DOE), Office of Energy Efficiency and Renewable Energy, Vehicle Technologies Office. Argonne National Laboratory is operated for DOE Office of Science by UChicago Argonne, LLC, under contract number DE-AC02-06CH11357.

\section{Author contributions}

Y.S.F., Z.W. and J.W.Z. conceived the research, designed experiments, and wrote the paper. L.Y., L.Y., Q.R.H. and Y.J.L. performed experiments. W.X.B. and P.C. performed SEM measurements. J.L., Y.Y., J.W.Z., X.W. and X.P.O. analyzed the data and provided necessary discussions. E.J.K. and C.X.H. conducted theoretical calculations. Y.Y., J.L. J.W.Z. and X.W. revised the manuscript. All authors discussed the results and commented on the manuscript.

\section{Competing interests}

The authors declare no competing interests.

\section{Additional information}

Supplementary information is available for this paper at https://doi.org/10.1038/s41467020-14686-2.

Correspondence and requests for materials should be addressed to J.Z. or J.L.

Peer review information Nature Communications thanks the anonymous reviewer(s) for their contribution to the peer review of this work.

Reprints and permission information is available at http://www.nature.com/reprints

Publisher's note Springer Nature remains neutral with regard to jurisdictional claims in published maps and institutional affiliations.

cc) (i) Open Access This article is licensed under a Creative Commons Attribution 4.0 International License, which permits use, sharing, adaptation, distribution and reproduction in any medium or format, as long as you give appropriate credit to the original author(s) and the source, provide a link to the Creative Commons license, and indicate if changes were made. The images or other third party material in this article are included in the article's Creative Commons license, unless indicated otherwise in a credit line to the material. If material is not included in the article's Creative Commons license and your intended use is not permitted by statutory regulation or exceeds the permitted use, you will need to obtain permission directly from the copyright holder. To view a copy of this license, visit http://creativecommons.org/ licenses/by/4.0/.

This is a U.S. government work and not under copyright protection in the U.S.; foreign copyright protection may apply 2020 